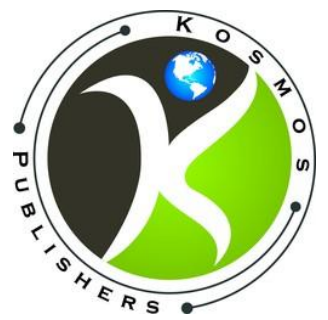

www.kosmospublishers.com contact@kosmospublishers.com

DOI: 10.37722/APHCTM.2021203

\title{
Research Article Advances in Public Health, Community and Tropical Medicine APCTM-127
}

ISSN 2691-8803

\section{Prevalence of Onychomycosis among food handlers in Owerri, southeast Nigeria}

\section{Uchegbu UN $\mathbf{N}^{*}$}

\author{
Department of Medical Laboratory Services, Federal Medical Centre, Owerri, Imo State
}

Received Date: August 13, 2021; Accepted Date: August 31, 2021; Published Date: September 08, 2021;

*Corresponding author: Uchegbu UN, Department of Medical Laboratory Services, Federal Medical Centre, Owerri, Imo State, +2348037090618. Email: druchegbujnr@yahoo.com

\section{Abstract}

This study focused on determining the prevalence of onychomycosis among food handlers between the ages of 1060 years in Owerri municipal, Imo State. 162 nail samples were examined microscopically with $20 \% \mathrm{KOH}$ for positive samples which were cultured on Sabouraud Dextrose Agar supplemented with both Chloramphenicol and Actidione, and incubated at room temperature for 21 days with constant check for growth on every day basis. The results show that, out of the 162 nail clipping samples, 97(59.9\%) were positive to fungal growth, while 65(40.1\%) samples were negative to onychomycosis. The fungi isolated were Candida albicans; 34(35.1\%), Trichophyton rubrum; 22(22.7\%), Aspergillus species; $15(15.5 \%)$, and non-albicans Candida; $12(7.4 \%)$. The age group of 30-40 years had the highest prevalence of onychomycosis; 34(35.1\%), whereas the age group 10-29 years yielded the lowest prevalence; 10(10.3\%). The female food handlers were found to be more prone to onychomycosis, although the prevalence varied across the locations. Compromise in personal hygiene and regular submergence of the hands into water greatly contributed to the prevalence of the condition.

Keywords: Food Handlers; Onychomycosis; Owerri; Prevalence; South East Nigeria

\section{Introduction}

Onychomycosis is a superficial fungal infection of the nails. It is the most common disease of the nail and constitutes about half of all nail abnormalities. This condition can affect the fingers or toe nails respectively. The nails are more infected because they are constantly exposed to moist and wet environment which encourages their growth [1]. They are caused by various species of Trichophyton and occasionally by Candida albicans.

Many look at onychomycosis as not debilitating and not life threatening, but World Health Organization (WHO) reports that millions of dollars is being spent annually for the treatment. This has raised our interest to investigate it, the possible treatment and preventive measures. It has also been found that there is paucity of information regarding onychomycosis and food handlers who most often immerse their hands in water due to their occupation in Owerri municipal.

The nail plate can have a thickened, yellow or crumpled appearance; it becomes toughened and can separate from nail bed. These are specific for onychomycosis can cause local pain, social embarrassment and affect quality of life. Nonspecific but common clinical findings include onycholysis, subunguial hyperkeratosis \& crumbling. The causative pathogens of onychomycosis include dermatophytes, yeast and nondermatophytic moulds. Among dermatophytes, the most often isolated causative pathogen is Trichophyton rubrum. Other common species are T. interdigitale (formerly T. mentagrophytes, Epidermophytonfloccosumand T. tonsurans in the temperate western countries. The most significant yeasts causing onychomycosis are Candida albicans and Candida parapsilosis are more frequently involved in the tropical and subtropical countries such as Nigeria, Jamaica, Thailand and Taiwan with hot and humid climate [2]. Trichophyton rubrum 
is the major cause of onychomycosis, after originating on West Africa, Southeast Asia, Indonesia and Northern Australia and South America in the late $19^{\text {th }}$ and early $20^{\text {th }}$ centuries [3].

Onychomycosis often results from untreated tinea pedis (feet) or tinea mannum (hand). It may follow an injury to nail, also, frequent immersion of hands on water on water e.g. in cooking or a cleaner may damage the protective skin at the base of the nail. This may allow fungi to enter. Also in diabetes patients, psoriasis, poor circulation, poor immune system, smoking in some cases, then fungal infection is likely to occur, to avoid misdiagnosis as psoriasis, lichen, planura, contact dermatitis, trauma, nail bed tumor or yellow nail syndrome, laboratory confirmation maybe necessary. The two main approaches are potassium hydroxide $(\mathrm{KOH})$, wet mount preparation, also known direct microscopy and fungi culture. This involves microscopic examination of culture of nail clipping or scrapings [4]. They are contagious and infection can spread from the nail (finger nail onychomycosis) to other part of the body. Infection can be transmitted among susceptible individuals which can lead patients to other serious complication. For instance in diabetic patients, onychomycosis can open the door to secondary bacterial infections promoting foot ulcers [5]. Onychomycoses also trigger recurrent cellulitis and thrombophlebitis [6].

Treatment of onychomycosis is challenging because the infection is embedded with the nail and is difficult to reach. Pharmacological treatments are either systemic antifungal medication such as terbinafine tablets and itraconazole tablets or topical (such as nail paints (nail lacquer) that contains the antifungal medicine amorolfine or tioconazole and nail removal an option to have the nail removal by small operation done under local anesthetic.

Newer options in treating fungal nail infections include; laser treatment and ultra sound. Oral antifungal medications usually are administered over a period of 3 months. Tropical antifungal treatment consists of the nail lacquer applied daily to affected nails. This treatment may irritate surrounding skin on rare cases, due to nail grow very slowly and receive very little blood supply, it typically takes 6 months to a year for the nail to regain a healthy, clear, then appearance [7].

These infections are frequently ignored because though they are not good to behold, they rarely cause discomfort. Some physicians refuse to treat onychomycosis despite the negative effect of the infection on patient health and quality of life. Physicians who feel it is unnecessary may regard it as a cosmetic problem rather than a health problem. Physicians may also be concerned that the risk of systemic therapy may outweigh the benefits. Attitudes towards onychomycosis and the people affected needs re-examination [8].

Onychomycosis is a chronic fungal nail infection that is not just an ailment or disease but one with a serious social stigma. Therefore, patients with onychomycosis may experience significant psychological and social problems due to the appearance of the nail. In view of this, the study focuses on exposing those measures that make the food handlers susceptible to onychomycosis. It has been found that food handlers are constantly exposed to wet environment through cooking and the frequent immersion of hands into water during the washing of plates and other dishes both before and after cooking the foods.

The humidity makes room for infection by Candida species, Aspergillus and some other dermatophytes which have marked predilection for wet environmental conditions. Controlling the recurrence of onychomycosis involves pharmacologic treatment and patients' education rather than a permanently curable disease. Patients should be given follow up treatment with topical antifungal agent after the initial episode has been successfully cleared. Patients presenting with both onychomycosis and tinea pedis, will also require an antifungal medication to resolve tineapedis. Treating tineapedis is important for preventing recurrence of onychomycosis because the fungal pathogens infecting the skin may act as a reservoir for re-infection of the nail. Patient education is just as important as pharmacologic therapy for controlling the recurrence of onychomycosis. These systemic drugs; terbinafine, itraconazole and fluconazole reach the nail via the peripheral circulation. Physicians need to explain to their patients the chronic infection and nature of the disease because patient needs to understand and take an active role in preventing future episodes of infection [3].

Some control measures for the prevention of onychomycosis include and are not limited to the following; clean and dry feet resist the disease, washing the feet with soap and water and drying thoroughly is the best approach, plastic hand gloves should be worn if possible on public functions, finger nails should be clipped across so that the nail does not extent beyond the tip of the nails, prolong immersion of hands in water should be avoided which promote moisture, instruments used to cut nails should be disinfected, polish should not be applied to the nails suspected of infection for example, those that are red, discolored or swollen, proper investigation before purchasing hand creams and in case of reaction during the use of hand cream discontinue [3].

\section{Materials and Methods}

\section{Study Area and Design}

The study was a cross sectional prospective study carried out in Owerri municipal where the food handlers make enough sales on daily basis. The area under study has a tropical climate and two main seasons, namely: rainy and dry seasons. The rainy season starts from March and ends about September, while the dry season starts from October and end by March. The places mapped out for sample collection included0: Relief market, Alvan Ikoku Federal College of Education (AIFCE), Imo State University (IMSU) back gate, Orji Market and Federal Polytechnic Nekede (FedPoNek). These places have areas chosen for the food handlers who are constantly patronized by the populace within the locality for 
the sake of cost considerations. The food handlers cook, wash and serve native cuisine to their customers.

Nail clippings were collected from male and female food handlers within the ages of 16-50years between March-August 2019.162 nail clippings were collected from 100 females and 62 males who were actively involved in cooking and washing of dishes in each eating spot. A structured questionnaire form was issued to gather data on the general information about the Participants who gave their full consent before sample collection.

\section{Assessment of Participants and Sample Collection}

An oral Ethical Approval was obtained from the Market Leaders of the chosen study areas. The assessment of the participants was conducted through an interview by using a questionnaire item prepared and collection of specimens for fungal studies. All subjects completely filled a questionnaire form providing useful pieces of information about themselves based on age, gender, patient's history of nail care and each of their work specification and roles in the eatery either washing, cooking and serving.

The obviously infected finger nails of the participants were sterilized with $70 \%$ alcohol and with sterile surgical blades, the nail clips were collected aseptically into a clean plain white paper, folded and taken to the Medical Microbiology Laboratory for processing. A total of 162 nail clippings (100 females and 62 males) were collected from the IMSU, AIFCE, Orji market, Relief market and FedPoNek food handlers and their age range from 16-50 years old and their attendants especially those that wash the dishes before and after cooking the served foods and the samples transported to the laboratory within 24 hours for processing.

\section{Processing of Samples}

\section{Direct Microscopy}

A portion of the nail clippings was used for direct microscopy on a grease free slide with $20 \% \mathrm{KOH}$. This was covered with cover slip and passed over flame about 3times to quicken the dissolution of keratin on the nail clippings.

\section{Culture}

The remaining portion of the specimen was seeded onto Sabouraud Dextrose Agar (SDA) supplemented with $0.05 \mathrm{~g}$ of Chloramphenicol(SDA+C) to help inhibit bacterial growth, and another SDA+Cto which $0.05 \mathrm{~g}$ Cycloheximide (Actidione) was added $(\mathrm{SDA}+\mathrm{C}+\mathrm{A})$. The preparation was incubated at room temperature for 14 days with daily check for obvious growth.

\section{Identification and Characterization}

The identification of the fungi isolated was based on macroscopic and microscopic examinations; surface morphology, reverse pigmentation and Germ tube test.

\section{Microscopic examination}

A small portion of the fungal growth was mixed with Lactophenol cotton blue stain on agrease free slide, covered with a slip and viewed under $\mathrm{x} 40$ Objective of the microscope. Germ tube tests were also carried out to differentiate Candida albicansfrom the non-albicans candid isolates.

\section{Results}

The results show that both dermatophytes and nondermatophytes were isolated as etiologic agents of onychomycosis from the nail clippings. The age group 16-22 years had the lowest percentage prevalence of 10(43.5\%), 2329 years yielded $12(48.0 \%), 30-36$ years with $34(63.0 \%)$, 3743 years with $24(65.0 \%)$ and age group $44-50$ had the highest percentage prevalence of $17(74.0 \%)$.

The most frequent fungal organisms isolated were Candida albicans: 34(21.0\%), non-albicansCandida; 26(16.0\%), Trichophyton rubrum; 22(14.0\%) and Aspergillus species $15(9.3 \%)$.

\begin{tabular}{|c|c|c|c|c|c|c|}
\hline Collection site & $\begin{array}{c}\text { Number of } \\
\text { Samples }\end{array}$ & $\begin{array}{c}\text { Candida } \\
\text { albicans }\end{array}$ & $\begin{array}{c}\text { Non-albicans } \\
\text { Candida }\end{array}$ & $\begin{array}{c}\text { Trichophyton } \\
\text { rubrum }\end{array}$ & $\begin{array}{c}\text { Aspergilluss } \\
\text { pecies }\end{array}$ & $\begin{array}{c}\text { Positive } \\
\text { cases }\end{array}$ \\
\hline AIFCE & 18 & $3(3.1 \%)$ & $2(2.1 \%)$ & $2(2.1 \%)$ & $1(1.0 \%)$ & $8(8.2)$ \\
\hline FedPoNek & 16 & $2(2.1 \%)$ & $1(1.0 \%)$ & $2(2.1 \%)$ & $2(2.1 \%)$ & $7(7.2)$ \\
\hline IMSU & 43 & $7(7.2 \%)$ & $10(10.3 \%)$ & $4(4.1 \%)$ & $1(1.0 \%)$ & $22(22.7)$ \\
\hline Orji Market & 60 & $18(18.6 \%)$ & $10(10.3 \%)$ & $5(5.2 \%)$ & $9(9.3 \%)$ & $42(43.3)$ \\
\hline Relief Market & 25 & $4(4.1 \%)$ & $3(3.1 \%)$ & $9(9.3 \%)$ & $2(2.1 \%)$ & $18(18.6)$ \\
\hline Total & 162 & $34(35.1 \%)$ & $26(26.8 \%)$ & $22(22.7 \%)$ & $15(15.5 \%)$ & $97(59.9 \%)$ \\
\hline
\end{tabular}

Table 4.1: Fungal elements isolated from the different food handlers. 


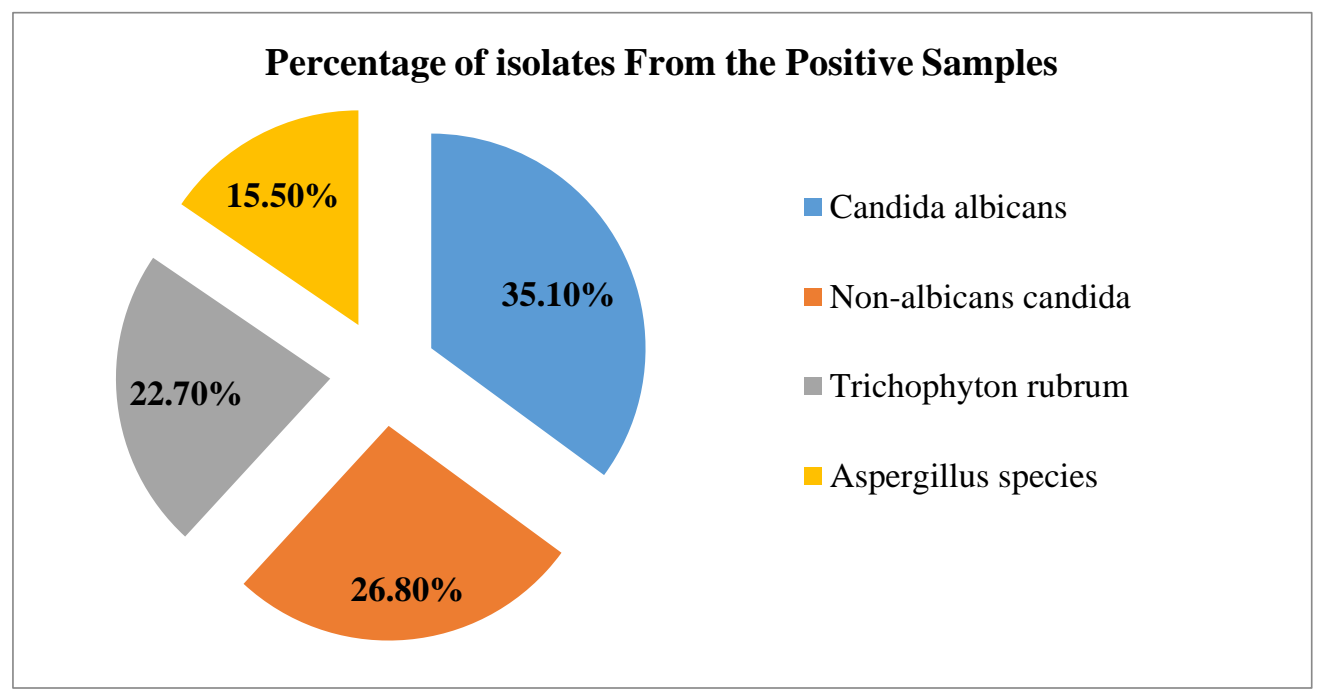

Table 4.2: Pie Chart Representing the Percentage of the Fungi Isolates among the Positive Samples.

\begin{tabular}{|c|c|c|c|}
\hline Age & Number of Samples & Positive Cases & Prevalence (\%) \\
\hline $16-20$ & 23 & 10 & $10.30 \%$ \\
\hline $21-24$ & 25 & 12 & $12.40 \%$ \\
\hline $25-40$ & 54 & 34 & $35.10 \%$ \\
\hline $37-45$ & 37 & 24 & $24.70 \%$ \\
\hline $46-60$ & 23 & 17 & $17.50 \%$ \\
\hline
\end{tabular}

Table 4.3: Age Distribution of Fungal Elements Isolated.

\begin{tabular}{|c|c|c|c|c|}
\hline \multicolumn{2}{|c|}{ SEX } & \multirow{2}{*}{ Number of Samples } & $\begin{array}{c}\text { Positive } \\
\text { Cases }\end{array}$ & Prevalence (\%) \\
\hline Female & Male & 23 & 10 & 10.3 \\
\hline $14(14.4 \%)$ & $9(9.3 \%)$ & 25 & 12 & 12.4 \\
\hline $16(16.5 \%)$ & $9(9.3 \%)$ & 54 & 34 & 35.1 \\
\hline $30(31.0 \%)$ & $24(24.7 \%)$ & 37 & 24 & 24.7 \\
\hline $20(20.6 \%)$ & $17(17.5 \%)$ & 23 & 17 & 17.5 \\
\hline $13(13.4 \%)$ & $10(10.3 \%)$ & &
\end{tabular}

Table 4.4: Sex Distribution of Fungal Elements Isolated from the respective locations.

\begin{tabular}{|c|c|c|c|}
\hline Fungal Isolates & Samples Examined & Frequency & Percentage (\%) \\
\hline Trichophytonrubrum & 162 & 22 & $22.70 \%$ \\
\hline Candida albicans & 162 & 34 & $35.10 \%$ \\
\hline Non-albicans Candida & 162 & 26 & $26.80 \%$ \\
\hline Aspergillus species & 162 & 15 & $15.50 \%$ \\
\hline Total & & 97 & $59.90 \%$ \\
\hline
\end{tabular}

\section{Discussion}

Onychomycosis is a common infection of the nails by fungi, and has been recognized as being a very difficult type of fungal infection to treat, although proven not to be life threatening. This infection constitutes public health problem and social dissatisfaction among those who have the disease because the distal extremities of the phalanges lose their aesthetics from the distortion. The disease can have certain negative consequences on the patients, such as pain and can
Table 4.5: Percentage of the Fungal Isolates from the whole samples.

potentially undermine their work and social lives [5]. With regards to food handlers in Owerri municipal, moist environment favors the growth of the fungal organisms which cause this infection; this inference agrees with the findings of previously done works $[\mathbf{9}, \mathbf{1}, \mathbf{1 1}]$. From their reports, the following assertions were deduced: low immunity can escalate the effects ofonychomycosis, people with obvious immune compromised conditions like Diabetes mellitus and HIV/AIDS are highly predisposed to this infection, dirty nails, and allowing the nails to grow without care (poor 
hygiene).Constant dipping of the hands in water is reported to be a high risk factor to these persons which is a commoncharacteristics of the food handlers.

The study reveals that, 97(59.9\%) specimens were positive in both culture and direct microscopy (see table 1). And 65 $(40.1 \%)$ of the nail samples were negative in both culture and direct microscopy. The disease is known to occur at any age, but more common between 25 and 45 years and is unusual prior to puberty because the keratin which the organisms relish on are more prominent at post-pubertal ages (12). But in this study, $10(10.3 \%)$ of the patients showed the disease after puberty (i.e. 16-20 years of age). This agrees with the findings of Midgley et al. (11). Pierard et al. [12] reported that onychomycosis is more common in adults than in children, and its prevalence increases with age. Their research postulated that the slow rise/advance in age of the populace is the reason behind the rise in the incidence of onychomycosis.

In this study, the majority of subjects $80(82.5 \%)$ were below 50 years of age and the age group of 40 to 50 years contained a good number of onychomycotic cases. This observation is in agreement with other studies [13].

According to Alvarez et al.[14], onychomycosis has been more prevalent in women, and in this study, 97(54.4\%) of the participants with onychomycosiswere females.

Regarding etiologic agent, researchers have found Trichophytonrubrumas the most important dermatophyte isolated during their studies $[15,16,17]$, and have been primarily the cause of onychomycosis. However, this study deviates a little from their findings because Candida species; $46(70.5 \%)$ were found to be the most prevalent isolates followed by Trichophyton rubrum; $22(22.7 \%)$ which is a dermatophyte.

\section{References}

1. Perea SM, Ramos M, Garau A, Gonzales AR, Noriega J et al. (2000) Prevalence and risk factors of tinea unguium and tineapedis in the general population in Spain. Journal of Clinical Microbiology. 38:3226-3230.

2. Chi CC, Wang SH, Chou MC (2005) The causative pathogens of Onychomycosis in Southern Taiwan. Mycoses. 48:413-420.
3. Larone DH (1996) Culture and identification of dermatophytes. Clinical microbiology News L. 18:33-38.

4. Elewski BE (1998) Onychomycosis: pathogenesis, diagnosis and management. Clinical microbiology. 11:415-429.

5. Scher RK (1994) Onychomycosis is more than a cosmetic problem. Britain Journal of Dermatology. 130 (suppl. 43): 15 .

6. Doyle JJ, Boyko WL, Ryu S, and Gause D (2000) Onychomycosis among diabetic patients: Prevalence and impact of non fungal foot infections. Poster, 6:9-13.

7. Gupta AK, Jain HC, Lynde CW, Summerbell RC (2000) Prevalence and epidemiology of toenail onychomycosis in patients visiting physicians' offices, A multicenter Canadian survey of 1500 patients. American journal of Academic Dermatology. 43:641-648

8. Hecker D (1997) Current trends in onychomycosis therapy: A literature review. Mount Sinai journal of medicine. 64:399-405.

9. Herranz P, Garcia J, Pena JM (1997) Toenail onychomycosis In patients with acquired immune deficiency syndrome: treatment with terbinafine. Britain Journal of Dermatology. 137:577-580.

10. Jacobsen AA, Tosti A (2017) Predisposing factors for Onychomycosis. In: Tosti A, Vlahoric T, Arenas R. (eds) Onychomycosis, Springer cham.

11. Midgley G, Moore MK (1996) Nail infection. Dermatologyclinic, 14:41-49.

12. Pierard G (2001) Onychomycosis and other superficial fungal infections of the elderly: a pan-European survey. Dermatology. 202:220-224.

13. Arenas R, Dominguez-cherit J, Fernandez L (1995) Open randomized comparison of Itraconazole versus terbinafine in onychomycosis. International Journal of Dermatology. 34:138-143.

14. Alvarez M, Gonzalez LA, Castro CA (2004) Onychomycosisin Cali, Colombia. Mycopathologia. 158:181-186.

15. Andre J, Achen G (1987) Onychomycosis. International Journal of Dermatology. 481-491.

16. Brody N (1995) Cutaneous fungal infections: innovative treatment schedules with systemic agents. International journal of Dermatology. 34:284-289.

17. Greer DL (1995) Evolving role of non dermatophytes in Onychomycosis. International Journalof Dermatology. 34:521.

Citation: Uchegbu UN (2021) Prevalence of Onychomycosis among food handlers in Owerri, southeast Nigeria. Adv Pub Health Com Trop Med: APCTM-127. 